\title{
What can be learned from patient stories about living with the chronicity of heart illness? A Narrative Inquiry
}

\begin{abstract}
Background: Understanding the illness process from the patient's perspective provides caregivers valuable information on how to engage in best practices that create healing contexts for patients and their families across the illness trajectory.
\end{abstract}

Aims: The purpose of this qualitative inquiry was to learn, through the telling of their own stories, how older South Asian immigrant women experience living with heart illness long after discharge from the hospital.

Method: We used Narrative Inquiry to explore four older South Asian women's stories of living with the chronicity of heart illness. Narrative Inquiry is a personal experience method that explores and interprets the lived and told stories through the three dimensions of experience: temporality, sociality and place.

Design: Four South Asian immigrant women, all over the age of sixty, living with heart illness for over ten years, were recruited through a South Asian community centre. Although they spoke English, translator was available for support. In the first meeting, participants, as a group, were guided through Narrative Reflective Process (storytelling, metaphor, drawing and writing). In the second meeting, participants engaged in individual narrative-based interviews.

Outcomes: Key narrative patterns reveal the overarching stories: Immigrant, Family and Illness. These stories not only give patients voice, but allow caregivers a glimpse into the human experience of illness beyond hospitalization. Considering the increased migration of people around the globe, this knowledge is significant in provision of person-centred care.

Implications: Knowing about patient's illness experiences invites caregivers to reconsider person-centred care; namely it does not end with the hospitalization and the short-term follow-up visits at the outpatient clinics. We need to work together as inter-professional and interdisciplinary teams to thoughtfully and intelligently map out the stages of progressively chronic illnesses, and to seamlessly articulate them for all concerned, especially the marginalized populations, such as older immigrant women.

Key words: patient illness stories; older immigrant women; nursing; person-centred care; narrative inquiry; narrative reflective process 


\section{Patient Stories}

Although patient stories have permeated the literary landscape for centuries, they became more proliferate in healthcare contexts during the latter part of the twentieth century (Hawkins, 1999a; Schwind, 2004). The purpose of these stories is to give patients voice so that we, the caregivers, can learn how ill individuals and their families experience the effects of illness in their everyday lives. Understanding the illness process from the patient's perspective provides caregivers, and nurses in particular, valuable information on how to engage in best practices that create healing contexts for patients and their families. Considering the increased migration of people around the globe, this knowledge becomes even more significant. In this article we explore, using Narrative Inquiry (Connelly \& Clandinin, 1990, 2006), what we can learn from patient stories about their illness experiences. We discover what is possible through this exemplar of stories told by four older South Asian women, immigrants to Canada, living with heart illness long after discharge from hospital. Although the stories are told in Canada, the knowledge gained through this Narrative Inquiry is transferable to other international contexts to be considered for further inquiry into how we provide care, not only to older immigrant women, but to all others who live with long term illnesses.

In our inquiry we intentionally use the term "heart illness" to focus on the human experience of heart disease, whose effects go beyond the affected organ, to include the whole person, mind-body-spirit. We utilize the term 'heart disease', the more traditional and medicalized term, when referencing other studies or when referring to a medical diagnosis. For the same 
reason, we interchangeably use terms "chronicity", "long-term illness" and similar, to denote patient's lived experience of illness that is in a state of prolonged and/or progressive duration.

\section{Background Review}

Over two hundred thousand immigrants a year, many of whom are from South and East Asia, arrive and settle into the metropolitan centres of Canada (Census Canada, 2001; Guruge \& Collins, 2008; Hyman, 2007). Of the newcomers, women outnumber the men by two to seven percent (Guruge \& Collins, 2008). Immigrants, especially those from South Asia, arriving to North America, exhibit the highest prevalence rates and mortality risk for heart disease (Anand, et al., 2000; Gupta, Singh, \& Verma, 2006; Mathews \& Zachariah, 2008; Public Health Agency of Canada, 2009). As a result, South Asian community leaders continue to express concerns about heart disease in immigrant women and how these are being addressed by the host country's healthcare system (Carlsson, Kristofferzon, \& Lofmark, 2007; Davidson, Daly, Hancock, Chang, Moser, \& Cockburn, 2003; Guruge, 2007; Morrison, Guruge, \& Snarr, 1999; Rajadurai, et al., 2012). The goal of heart disease treatment has evolved into a strategy of prevention and symptom management with the intent of improved functional status and enhanced quality of life (Todero, 2002). Research shows, however, that despite treatment, people with heart disease often continue to experience symptoms that limit activities, which contribute to decreased quality of their life and often lead to consumption of medical resources through emergency treatments, hospitalizations, and readmissions (Greenwald \& Jack, 2009; Hauptman et al., 2008; Yu, et al., 2007).

A serious illness, such as heart disease, often brings chaos, fear and uncertainty into the lives of patients and their families. Such turbulent disruptions are magnified when the ill person and her family are also immigrants who are trying to reconcile discontinuities of fragmented 
narratives of relocation, reconfigured social network, and precarious economic status. The quality of life as reported by immigrant women changes significantly once their lives are interrupted by illnesses such as heart disease (Moser, 2007; Plach \& Heidrich, 2001; Zeilani \& Seymour, 2012). Patients' lives, and the lives of their families, are considerably impacted, causing anxiety, a sense of vulnerability and a loss of control (Brink, Hallberg, \& Karlson, 2005; Howard, Bottorff, Balneaves, \& Grewal, 2007; Wang, et al., 2007; Whitsitt, 2012). Such treatments as modifications in diet and activity levels, and management of medications become an additional challenge to the physical changes and fatigue related to a cardiac event (Wang, et al., 2007). It is important to note that for the most part, these research studies have not focused on the unique experiences of immigrant women with persistent heart disease. In fact, to date no data has been located on how older South Asian immigrant women, in particular, experience living with heart illness long after discharge from the hospital, suggesting further research is needed in order for them to receive more effective ongoing care and support (Bekelman, et al., 2007; Dickstein et al., 2008). The purpose of this qualitative study is to give voice to patient's experience of living with the chronicity of heart illness. More specifically, using Narrative Inquiry, we explore what is possible to learn through the exemplar of four older South Asian immigrant women's stories of their experience living with heart illness beyond hospitalization. This then leads to the inquiry puzzle: How do older South Asian immigrant women experience living with heart illness long after discharge from the hospital?

\section{Inquiry Design and Process}

\section{Method}

Since the intent is to learn how these women experience living with heart illness, Connelly and Clandinin's (1990) Narrative Inquiry qualitative research approach is used. 
Narrative Inquiry is a personal experience method that explores and interprets the lived and told stories through the three dimensions of experience, referred to as common places: temporality, sociality and place (Connelly \& Clandinin, 2006, p. 479 - 481). Thinking narratively, this means that life events are understood to happen over time, within a relationship and in a physical place or a series of places. In our study, women's stories, represented as one composite story, express the temporal nature of their life events that take place between two countries, in their homes and workplaces, and in the hospitals. Each of their accounts reveals personal and professional relationships that impact their respective illness trajectories. These commonplaces thus call a closer attention to the complexity of storied experiences by contextualizing women's present situation of living with illness within past life events, as well as in their hopes for the future.

\section{Participants}

The four women Karima, Saraja, Dosha, and Marinder (all pseudonyms), who responded to our call to participate in this qualitative study, were recruited through a South Asian community centre in Ontario, Canada. All are over the age sixty, and have been living with heart illness for over ten years. It is significant to note, however, that although these women know they have heart disease, they know neither the cause nor the exact diagnosis of their illness. Their primary languages are: Gujrati, Tamil, or Hindi yet, all women can speak some English. Translator, who speaks English and all three primary languages, assisted when clarity of communication was wanting. In addition to diagnosed heart disease, these women also suffer from hypertension, shortness of breath, high cholesterol, and diabetes. Ryerson University's Research Ethics Board (REB) approval was received. This REB approval was accepted by the community centre where participants were recruited. Informed consents were obtained from participants and their translator. 
Inquiry Process Stories were collected in two stages two weeks apart. In the first meeting participants were guided through the Narrative Reflective Process (NRP) (Schwind, 2008, 2014), which incorporates storytelling, metaphor, drawing and writing. This creative data collection tool grows out of Narrative Inquiry and helps participants elicit multidimensional narratives of their experiences. The work with creative expressive modes facilitates reflection and accesses tacit knowing that might not be readily reachable by traditional interviews alone (Polanyi, 2009/1966; Schwind, 2003; Schwind, Santa Mina, Metersky \& Patterson, 2015; Schwind, Zanchetta, Aksenchuk \& Gorospe, 2013). For the first meeting of this study we met together as a group; here women told stories of their significant life-events and they drew metaphors of their respective illness experiences. We felt that women, who already knew each other from the community centre, would feel more comfortable sitting around a table talking about their life experiences, which they did. They affirmed one another through supportive gestures and comments. Drawing together in a group was also less stressful for them, as they were able to converse with each other and exchange light hearted comments about their drawing abilities during the process.

At the second meeting following the creative group work activity we engaged the women in individual semi-structured narrative-based interviews. The iterative questions flowed out of the first meeting's conversations about their immigration, their family and work life, and significantly, their illness experiences. The conversations from meeting one and individual interviews from meeting two were audio-taped and transcribed. One woman declined the individual interview. Gathered field text (data) was reviewed and critically reflected upon. Collected stories, expressed through art and telling, were deconstructed and significant narrative patterns identified, forming the Overarching Stories, as discussed below. Further critical reflection 
searched out the significance of these narrative patterns and their constituent narrative threads through the three levels of justification: personal, practical and social (situating the study within extant literature and considering its significance in the greater professional and social contexts) (Clandinin \& Connelly, 2000; Clandinin, Pushor \& Orr, 2007). The personal level of justification calls for the researcher's responses as she engages with the told stories. At the practical justification level the researcher considers participants' stories within the context of nursing/healthcare profession, while incorporating relevant scholarly work. And, at the social justification level, researcher situates the current inquiry within the broader research literature and considers its significance in the greater social context. Although the three levels of justification are often intertwined, the personal justification is evident as each overarching story is discussed, while the practical and the social justifications represent the bulk of the discussion section.

\section{Critical narrative reflection on patient stories}

In order to protect the identity of the four women who belong to a relatively small local community, we have crafted a composite story using participants'/translator's collective words and phrases as an exemplar of their experiences living with heart illness. Using composite stories in Narrative Inquiry serves just that purpose, to give voice to significant life experiences while protecting the identity of the storytellers (He, 2000; Lindsay, Cross, \& Ives-Baine, 2012;

Phillion, He, \& Connelly, 2005). To further support the analysis process, individual participant narrative segments are also shared where appropriate, without compromising their anonymity. Composite Story of Living with Heart IIIness

I came to Canada from India 25 years ago with my husband and two children. I was a 
teacher in my home country so I never had to do any physical work. In Canada I worked very hard in the factory for fifteen years to support my family. My husband did not work much. I looked after my old mother, brought up my children and looked after my grandkids. I started having heart trouble one day when I was at work. I told my supervisor and he sent me home. I came back to work the next day. The pain returned and I was taken to the hospital. I think I had a heart attack. Now I need to take a lot of big pills and I don't like that. I need to buy my own medication, which is very expensive. I was laid off from my work after my heart problem. It is hard for me to walk. I get short of breath and need to rest, but I try to be as active as possible. I try to control my high blood pressure so I don't fall again. I try to eat right, but it's hard since I like Indian food. I cannot eat salt, sugar, oil and fat, which is hard to do. I try to cook for myself, but because I cannot see well anymore I often go hungry all day. I need help. But, since I have heart problem there is no one to help. I have kids, but they don't visit; they are too busy with their own children and with work. I am now separated from my husband. I am lonely. I have faith in God that he will take care of me. I try to go to the community centre and to the Temple whenever someone can take me there. I am afraid of what will happen to me. But, I live a very happy life!

What follows is the exploration of how the older women we spoke with make sense of their life events, and how we, the caregivers, could learn from their stories to offer more meaningful person-centred care beyond the discharge from the hospital post cardiac event. The following narrative threads intertwine to inform the Overarching Stories, the narrative patterns: Illness Story (burden of illness and restricted life); Family Story (family relationships and loneliness); and Immigrant Story (language skills and uncertain economic status). 


\section{IIIness Story}

Burden of illness. The stress endured through a lot of hard work at home and in the factory was compounded without the social supports that were available to them in their country of origin. All four women ignored the first signs of chest pain. They either tried to treat the pain themselves or they looked for external validation and direction from their work supervisor or a family member. It took several days and repeats of chest pain before they sought healthcare. Saraja shares, through the translator, her experience of chest pain: I had some chest pain, so I took one clove of garlic and swallowed it. I felt better, so I kept quiet. I had it 4 or 5 times. When I had it bad, my husband called the ambulance. I was hospitalized and had a bypass. After surgery I could not eat salt, oil and fat, but that is difficult for me.

Dosha shows her drawing of a heart and a flower. The translator communicates Dosha's explanation, "Now I'm better. Have hopeful heart. Life has been hard, but I'm happy now. I've been pretty okay after the medicine." Dosha's drawing gives a sense that being ill was not something to acknowledge or complain about, but rather to show how even the hardship is valiantly handled. Marinder's response to how her heart illness impacts her life aligns with Dosha's view, "Nothing. Normal life. I don't need help from them [her children]."

Women seemed to view their heart event as a 'problem with them', that somehow they 'deserved' the illness, and therefore it was their burden to bear alone; they were accepting of their diminished value to the family. Karima's tone of voice and her words betray a sense of guilt that she caused her illness. Her son came to see her in the hospital, "He was shocked, and he said 'What happened?'. I said, I don't know. They said a heart attack." Women expressed a sense of resigned acceptance, which may be related to the stage of their life, illness, loneliness, and perceived lack of usefulness to family and society. Marinder talks about her drawing, which 
depicts her life before and after becoming ill. (Fig. 1) She tries to make sense of it for herself: I make a flower ... I know I have problems ... My auntie die, so I die too. I don't know when I die ... That's why I have sometime happy, sometime no good ... Dry leaf, I'm sad ... flower, I'm happy. Too many medications for life ... stressed and worried ... so no time to think about this heart ... Who has [time] to learn or talk about this? This sense of burden, sacrifice, and hopelessness is also expressed by Karima, as she talks about her drawing (Fig. 2): “It is becoming slowly down. My heart is always bleeding ... pain. I'm so sick that I cannot even walk. I have to walk with a stick. I'm old. My disease is killing me." Her tone of voice is one of resignation, as she pauses to accommodate her shortness of breath. She is all too cognizant of the gravity of her health state.

Restriction of activity and movement. Reconstructed stories paint a picture of heart illness as an illness of loneliness, isolation, and a broken heart. When Karima asked her doctor the reason for her hospitalization the doctor told her to "keep quiet". There is a lot of restriction on women's voices: not allowed to know, not telling anyone, not allowed to speak, being told by the doctor not to speak, and voluntarily not telling others of their illness. Social, and possibly cultural, norms about woman's place and role also interplay with this cessation of voice, to be seen, to be of service to others, but not to complain, along with not being "deserving" of answers and explanations, or even family care.

Women also experienced restriction of activity at different levels: Physically, due to cardiac insufficiency women are unable to move as quickly or walk as far as they used to previously. There is a greater reliance on medications to provide them with sufficient relief to more easily move around and carry out the basic activities of daily living. Developmentally, the 
four women who shared their illness stories are older. Women are also socially restricted because they do not have means to travel on their own. Additionally, lack of English speaking skills restricts their awareness and knowledge of what is available to them within the Canadian social healthcare system. These women go to the Temple, but when they are feeling unwell they are unable to attend, resulting in further social isolation. However, the four women have found their way to the local South Asian community center where they meet peers with whom they can talk and socialize.

\section{Family Story}

Family Relationships: These women express a strong sense of responsibility and duty to the family. Most of her adult life Marinder felt emotionally stretched and physically exhausted by looking after her family while working long hours at the factory. Being caught between the traditional role of woman, wife, mother and daughter, between home country and the adoptive one, she had no time or energy to pay attention to her own health. 'We, as a family unit, are doing well', seemed to be the message all four women wanted to portray. This brings to mind Goffman's sociological theory (1959) of the tensions we often experience between our personal and public lives. Using the metaphor of theatre, he speaks of human predilection to present the best self to the audience in order to avoid embarrassment. Similarly with these women, there was a reluctance to share too much information about family challenges. It seemed as if they tried to put up a positive front to the world so as not to be 'disloyal' to their own families. This is astutely evident in the composite story, where the account speaks of numerous life challenges, yet ends on a reassuring positive note "But I live a very happy life!"

Loneliness and a sense of rejection. Loneliness and a sense of rejection by their adult 
children and by society became evident in our conversations, and especially so in their drawings. Women repeatedly stated, "I'm happy", and yet their drawings betrayed feelings of loneliness. All four women seemed to measure their own success through that of their children: if the adult children were doing well, the family was 'successful'.

Despite selfless care for the family and kids' education, now when the children are independent, the ageing mothers are often 'forgotten'. Yet, daughters are often seen as a 'blessing', because they can talk and understand one another (Grewal, Bottoroff, \& Hilton, 2005). Sons, on the other hand, are held with pride, and someone to whom the ageing mother looks up. Daughters- in-law are perceived as, and expected to be, 'not caring'. As translator speaks, Dosha interjects (in italicized font) about her current life situation: Son is too busy ... daughter-in-law doesn't care ... so she's at home by herself ... and sit and no help... When she doesn't feel good she's hungry all day because she doesn't see well enough to make a meal. No my children really busy, no look up. Life is too much busy. They [children] don't do, don't care. They even took the money, but they don't take care. Two daughters-in-law never come. Sometimes feels weak to go to the Temple.

She's alone at home and so lonely, so she comes here to the [community] centre. Saraja also feels lonely and alone, dependent on others to get out of her apartment to be amongst people. The translator usually keeps an eye on her and takes her to the community centre, where she meets with other South Asian women. Karima too is lonely, so she comes to the centre by taking assisted city transit. This sense of loneliness and being forgotten was also evident in another study on experiences of loneliness among older Sinhalese immigrant women (Madhavi, Guruge, Schwind, \& Schindel Martin, 2014). However, Marinder tries to make light of her, and other women's situations, "How many women live alone? Lonely? Yeah. When they [children] 
grow they go, they need money."

\section{Immigrant Story}

Language skills. When Karima wanted to learn how to speak English, her husband deterred her from taking classes, saying 'Why do you want to learn English?' She was expected to look after the family and to work, but do nothing for herself. She expressed regret all these years later for not insisting on her desire to learn how to speak English, so that she would not feel so constrained in her life options.

Uncertain economic status. Both Marinder and Dosha lost their jobs. They speculate it was due to their heart problem, as well as their age. They worked at low paying jobs with no job security and no health or pension benefits. Marinder shared what happened to her and her husband after working at their respective jobs for over 20 years, Me no job 2002 September and my husband [...] lose his job in January, 2003. [...] I look really hard everywhere looking for work, work, work, but everybody hire now teenager. Husband worked hard for many years, he got nothing [...] No benefits so have to buy medicines on my own.

\section{Research Process Challenge Overcome}

As Narrative Inquiry is a co-constructive personal experience method, the challenge researchers sometimes broach is the researcher - caregiver role boundary. During the data collection meetings with the four participants the first author was intensely aware of her struggle keeping the role of a researcher and not slipping into the role of a caregiver. During her conversations with the women she felt a need to teach/educate/inform these 'patients' (the four participants) about the possible reason for their health struggles, and to help them understand the heart disease process. She did not do that. However, in order to express her gratitude to the 
women for sharing their stories with her and to support them, as well as the rest of the older women's group, two research team members presented an interactive 'Healthy Heart' workshop to all the women in the community centre. The experiential presentation was well received and appreciated by the community members.

\section{Discussion}

Situating our inquiry within the existing literature on illness, such as heart disease, (Carlsson, et al., 2007; Greenwald \& Jack, 2009; Guruge, 2007; Rajadurai, et al., 2012; Zeilani \& Seymour, 2012) brings to the forefront the importance of also including the patient's voice when investigating possible treatments. This allows us, the caregivers, the opportunity to see the illness from the other side (Schwind, 2004; Winawer, 1998), and so supports person-centred care that is more inclusive and whole (Schwind, Lindsay, Coffey, Morrison, \& Mildon, 2014). Narrative Inquiry data analysis brought to the surface the immigrant experience as it revealed itself through the stories of the ill heart. Tensions often associated with post-migration experiences became evident: past-present; belonging-loneliness; generativity-rejection; and selfsacrifice - self-care. Narrative threads interwove the three overarching stories, the narrative patterns, Illness, Family and Immigrant. Usually, our primary story is the Family story. However, once people leave their homeland, their primary story is superseded by the Immigrant story, as this narrative colours everything else that happens in this individual's family life. In other words, the Immigrant story becomes the lens through which all the other narratives, past, present and future, are lived out and interpreted (Grewal et al., 2005; Hyman, 2007; Lim \& Ng, 2010; Schwind, 2004).

Upon arrival in their newly adopted country, immigrants often experience a transition period during which they must become self-sufficient to support themselves and their families 
(Hyman, 2007). Migration also results in leaving behind larger family and community structures and supports. As a result, in their adoptive country, the immigrants begin to rely heavily on their nuclear family. The family, because of this transplantation, is often culturally and socially isolated, on the basis of language, differing cultural practices and beliefs, nutrition, and sheer lack of their own kin (Lim \& Ng, 2010). During this time, the stress of illness combined with immigration can potentially lead to negative health outcomes for immigrant women and their families (Hyman, 2007). Immigrant women, who are often central figures within their families, when afflicted by heart disease experience added stress of reconciling the new sick role with the expected family role. This is further accentuated by the lack of social and societal supports, whether actual or perceived (Grewal et al., 2005; Madhavi et al., 2014).

The first overarching story in this study, the Illness story, is tinged by both the Immigrant and the Family stories. How illness is experienced is tinted by these overarching stories that bleed their contexts and dimensions of time through each experience, often twisting and turning it until the individual knows not what else to do, but to resign herself to the events that potentially threaten her life. This sense of resignation, which, when coupled with strong spirituality, is a form of acceptance of life circumstance; this is evidenced in the composite story where women talk about loneliness and going hungry, yet they finish the story with a positive note. Their stories also suggest they saw their diagnosed heart disease, or any other hardship for that matter, as their own problem to deal with. Consequently, they made no complaints to their family, and they had no requests or suggestions for improvement to the healthcare system in the provision of long term care post discharge.

Time and again the only continuing narrative thread that seems to cross all stories is the individual's spiritual strength. This connection and belief in God is also expressed by the four 
women through their conversations about going to the Temple, as well as through their drawings; Saraja drew herself sitting alone on a chair and reading the Bible. (Fig. 3) For these women spirituality is a grounding thread, which provides a perspective that helps them find meaning in their reconfigured life within the transplanted landscape. In this way illness experiences also have the potential for positive effects in the immigrant women's lives of renewed and enhanced faith (Wang et al., 2007). Illness stories reveal "cultural attitudes and assumptions about illness, treatment, and recovery" (Hawkins, 1999b, p. 129). Hearing these older women's stories allows us a glimpse at what heart illness looks like from their perspective as they live its progressive chronicity on a daily basis, well after the discharge home from the hospital. These illness narratives present us, the caregivers, with the opportunity to learn what we can do to make changes in our respective roles that support person-centred care to all patients, no matter their demographic, and no matter at what point of disease trajectory they may stand. For caregivers then, the stories of illness are a "gold mine of patient attitudes and assumptions regarding all aspects of illness" (Hawkins, 1999b, p. 127). As such, illness narratives have the potential to transform the lives of patients, families, communities and caregivers.

With Narrative Inquiry in particular, the value of told stories is in how effectively the researchers and the readers are drawn into their own inquiry to change practice, their own and that of the greater healthcare system, no matter where they are located in the world. The stories told by the four older South Asian immigrant women support person-centred care by giving voice to patients' illness experiences; in turn providing us with the opportunity to reflect on our own healthcare practices. For example, the first author writes how she entered her own inquiry as 
a result of hearing the women's stories: As I reflected on the women's stories I was brought into my own inquiry of how I experience being an immigrant, plucked out of a familiar environment of supportive family and community and brought into a new country, with a different language and strange to me social norms. Although I was a young person when we came to Canada, these women's stories connected with mine: the immigrant story became the lens through which my family story unfolded and through which I lived my own illness story. Over the years these narrative patterns and their component narrative threads in my life have become softened, faded and more pliable, as they interweave through time and across different contexts. Professionally, by hearing these women's stories my own narrative patterns shifted and became enriched. For example, as a nurse-teacher, this increased awareness now informs my teaching-learning situations with my senior undergraduate students. I raise their awareness and foster their advocacy through dedicated discussions on how we provide person-centred care to all patients long after their discharge from the hospital, and especially to the marginalized populations like older immigrant women.

These illness narratives will help inter-disciplinary healthcare teams develop more effective and meaningful sociocultural interventions and guidelines that address the complex needs of this, and other immigrant populations. More specifically, this Narrative Inquiry is a call to healthcare practitioners, as well as to the governmental policy makers, to re-vision the disease trajectory, when it begins and when it ends, and by implication, where our involvement enters and leaves this development. We believe it is beneficial to the patients and their families, as well as to the healthcare providers, to be aware of how older South Asian women experience heart illness in the aftermath of active treatment and well after discharge back into the community. 
Knowing about their illness experience invites the healthcare educators and providers to reconsider what providing person-centred care actually entails; namely it does not end with the hospitalization and the short-term follow-up visits at the outpatient clinics. We need to work together as inter-professional and inter-disciplinary teams to thoughtfully and intelligently map out the stages of progressively chronic illnesses, such as heart disease, and to seamlessly articulate them for all concerned. Particularly, we are referring to the health promotion branch, to disease treatment stage, to recovery phase and finally to living long-term in the community with the repercussions of a progressive chronic illness, such as cardiac disease. We recognize that strides are being made in this direction (Baker, 2010; Courtney et al., 2009; Ebrahimi, Wilhelmson, Dea Moor, \& Jakobsson, 2012; Enguidanos et al., 2012; Johnson, 2000; Watkins, 2012; Wong et al., 2008; Wong et al., 2011), but we need to more intentionally ensure that all the stakeholders are keenly on board for all the patients, providing proactive skillful and meaningful care over the long term post discharge from the hospital. Accordingly, these tailor-made guidelines, through culturally sensitive and appropriate support and education (Banerjee et al., 2010; Galdas \& Kang, 2010; Leininger, 2007; Wang et al., 2007), could promote greater observance by all patients to prescribed treatment programmes, potentially decreasing the number and the intensity of their heart disease symptoms and related re-hospitalizations; this could in turn improve their quality of life, as well as lessen healthcare costs. This alone, could be the value of hearing these women's stories. However, with Narrative Inquiry, as with other qualitative research, the results of this study are transferrable, through the reflective inquiry by the reader, to other patient populations and to other contexts. Thus, these suggested approaches carry the potential to inform the greater social healthcare structures around the world on how to augment the long term support of all who live with progressive chronic illnesses. 


\section{Concluding Remarks}

With this study we contribute substantive qualitative data to the extant literature on immigrant older women's experience of heart illness; it serves as an exemplar and thus as an encouragement for eliciting further patient stories, from which we the caregivers could learn how to augment our caring practices. More specifically, through this Narrative Inquiry of older South Asian women's experiences living with heart illness we glean an understanding how patient stories could positively impact how we provide person-centred care to those living with progressive chronicity of illness. Furthermore, through this inquiry we re-affirm the struggles of immigration from the patient's perspective: challenges with new language speaking skills, lack of extended family supports, and the sociocultural barriers to implementing prescribed treatments for the long term. These women's stories also reveal poverty and loneliness, something that is not exclusive to immigrant women, but to aging women in our societies (Davidson et al., 2011), which requires closer scrutiny; this is especially significant considering the progressively ageing populations world-wide. Consequently, further research is needed into the effective and meaningful long term spiritual and sociocultural healthcare support of all aging individuals in our communities, living with progressive chronic illnesses.

In addition to the above, through this inquiry we also demonstrate that using a creative data collection tool, such as Narrative Reflective Process, allows more complete and authentic stories to emerge. The tacit and embodied knowing that can often be easily censored in traditional interviews became apparent through the creative self-expression of storytelling, metaphors and drawing. Such activities can also be undertaken by any member of the interdisciplinary team in order to develop self-as instrument of care (Schwind, Cameron, Franks, Graham, \& Robinson, 2012; Lindsay \& Schwind, 2014). Through increased self-awareness and 
personal knowing, these caregivers are then able to extend such opportunities to those in their care, to help them surface and reconstruct their own experiences of illness. Thus, using creative self-expressive tools to elicit authentic stories opens a window into a deeper layer of knowing that informs our everyday ways of being, thinking and doing.

\section{References}

Anand, S. S., Yusuf, S., Vuksan, V., Devansen, S., Teo, K., Montague, P. A., Kelemen, L., Yi, C., Lonn, E., Gerstein, H., Hegele, R. A., \& McQueen, M. (2000). Differences in risk factors, atherosclerosis and cardiovascular disease between ethnic groups in Canada: The study of health assessment and risk in ethnic groups (SHARE). Lancet, 356(9226), 279284.

Baker, S. J. (2010). Post-visit phone calls save lives, improve clinical outcomes, and reduce 
readmissions. Journal of Emergency Nursing, 36(3), 256-259.

Banerjee, A. T., Faulkner, G., Grace, S. L., \& Thomas, S. G. (2010). Cultural factors facilitating cardiac rehabilitation participation among Canadian South Asians: A qualitative study.

Heart \& Lung, 39(6), 494-503.

Bekelman, D. B., Sydney, M. D., Becker, D. M., Wittstein, I. S., Hendricks, D. E., Tamashita, T. E., \& Gottlieb, S. H. (2007). Spiritual well-being and depression in patients with heart failure. Journal of General Internal Medicine, 22(4), 470-477.

Brink, E., Hallberg, L. R. M., \& Karlson, B. W. (2005). Readjustment five months after a firsttime myocardial infarction: Reorienting the active self. Journal of Advanced Nursing, 53(4), 403-411.

Carlsson, M., Kristofferzon, M. L., \& Lofmark, R. (2007). Striving for balance in daily life: Experiences of Swedish women and men after a myocardial infarction. Journal of Clinical Nursing, 16, 391-401.

Census of Canada 2001. Available, http:// www12. statcan.ca/English/census01/home/index.cfm. Accessed 7, 2008.

Clandinin, J., \& Connelly, M. (2000). Narrative inquiry, Experience and story in qualitative research. San Francisco: Jossey-Bass.

Clandinin, D. J., Pushor, D., \& Murray Orr, A. (2007).Navigating sites for narrative inquiry. Journal of Teacher Education, 58(21), 21-35.

Connelly, F. M., \& Clandinin, D. J. (2006). Narrative inquiry. In J. L. Green, G. Camilli, P. B. Elmore, A. Skukauskaite, \& E. Grace (eds.), Handbook of complementary methods in education research. (pp. 477-487). Washington, DC: Lawrence Erlbaum Associates, Inc. Connelly, F. M., \& Clandinin, D. J. (1990). Stories of experience and narrative inquiry. 
Educational Researcher, 19(5), 2-14.

Courtney, M., Edwards, H., Chang, A., Parker, A., Finlayson, K., \& Hamilton, K. (2009). Fewer emergency readmission and better quality of life for older adults at risk of hospital readmission: A randomized controlled trial to determine the effectiveness of a 24-week exercise and telephone follow-up program. Journal of American Geriatrics Society, 57, 395-402.

Davidson, P. M., DiGiacomo, M., \& McGrath, S. J. (2011). The feminization of aging: How will this impact on health outcomes and services? Health Care for Women International, 32, 1031-1045.

Davidson, P. M., Daly, J., Hancock, K., Chang, E., Moser, D., \& Cockburn, J. (2003).

Perceptions and experiences of heart disease: A literature review and identification of a research agenda in older women. European Journal of Cardiovascular Nursing, 2, 255264.

Dickstein, K., Cohen-Solal, A., Filippatos, G., McMurray, J. J. V., Ponikowski, P., PooleWilson, P. A., Stromberg, A., van Veldhuisen, D. J., Atar, D., Hoes, A. W., Keren, A., Mebazaa, A., Nieminen, M., Priori, S. G., \& Swedberg, K. (2008). ESC guidelines for the diagnosis and treatment of acute and chronic heart failure. European Heart Journal, 29(24), 2388-2442.

Ebrahimi, Z., Wilhelmson, K.,Dea Moore, C., \& Jakobsson, A. (2012). Frail elder's experiences with and perceptions of health. Qualitative Health Research, 22(11), 1513-1523.

Enguidanos, S., Gibbs, N., \& Jamison, P. (2012). From hospital to home: A brief nurse practitioner intervention for vulnerable older adults. Journal of Gerentological Nursing, $38(3), 40-50$. 
Galdas, P. M., \& Kang, H. B. K. (2010). Punjabi Sikh patients' cardiac rehabilitation experiences following myocardial infarction: A qualitative analysis. Journal of Clinical Nursing, 19, 3134-3142.

Goffman, E. (1959). The presentation of self in everyday life. NY: Anchor books.

Greenwald, J. L., \& Jack, B. W. (2009). Preventing the preventable: Reducing hospitalization through coordinated patient-centered discharge process. Professional Case Management, 14(3), 135-140.

Grewal, S., Bottorff, J. L., \& Hilton, B. A. (2005). The influence of family on immigrant South Asian women's health. Journal of Family Nursing, 11, 242-263.

Gupta, M., Singh, N., \& Verma, S. (2006). South Asians and cardiovascular risk: What clinicians should know. Circulation, 113, e924-929.

Guruge, S. (2007). The influence of gender, racial, social, and economic inequalities on the production of and the responses to intimate partner violence in the post migration context. Unpublished doctoral dissertation, University of Toronto, Toronto, ON Canada. Guruge, S., \& Collins, E. (2008). Emerging trends in Canadian immigration and challenges for newcomers. In S. Guruge \& E. Collins (Eds.), Working with immigrant women: Issues and strategies for mental health professionals. (pp. 3-15). Toronto, ON: Centre for Addiction and Mental Health.

Hauptman, P. J., Swindle, J., Burroughs, T. E., \& Schnitzler, M. A. (2008). Resource utilization in patients hospitalized with heart failure: Insights from a contemporary national hospital database. American Heart Journal, 155(6), 978-985.

Hawkins, A. H. (1999a). Reconstructing illness: Studies in pathography. West Lafayette, IA: Purdue University Press. 
Hawkins, A. H. (1999b). Pathography: Patient narratives of illness. Western Journal of Medicine, 171(2), 127-129.

He, M. F. (2000). A river forever flowing: Cross-cultural lives and identities in the multicultural landscape. Greenwich, CT: Information Age Publishing.

Howard, A. F., Bottorff, J. L., Balneaves, L. G., \& Grewal, S. K. (2007). Punjabi immigrant women's breast cancer stories. Journal of Immigrant Minority Health, 9, 269-279.

Hyman, I. (2007). Immigration and Health: Reviewing Evidence of the Healthy Immigrant Effect in Canada. Toronto, ON: Joint Centre of Excellence for Research on Immigration and Settlement-Toronto.

Johnson, K. (2000). Use of telephone follow-up for post-cardiac surgery patients. Intensive \& Critical Care Nursing, 16(3), 144-150.

Leininger, M. (2007). Theoretical questions and concerns: Response from the theory of culture care diversity and universality perspective. Nursing Science Quarterly, 20(1), 9-15.

Lim, L. L., \& Ng, T. P. (2010). Living alone, lack of a confidant and psychological well-being of elderly women in Singapore: The mediating role of loneliness. Asia Pacific Psychiatry, 2(1), 33-40.

Lindsay, G. \& Schwind, J.K. (May 2014) Arts-Informed Narrative Inquiry: Constructing Person-Centred Care www.theartofexperience.ca (website @ 2014).

Lindsay, G., Cross, N., \& Ives-Baine, L. (2012). Narratives of neonatal intensive care unit nurses: Experience with end-of-life care. Illness, Crisis \& Loss, 20(3), 239-253.

Madhavi, A. V. P., Guruge, S., Schwind, J., \& Schindel Martin, L. (2014) Exploring the experiences of loneliness among older Sinhalese immigrant women in Canada.

Perspectives, 37(1), 6-14. 
Mathews, R. \& Zachariah, R. (2008). Coronary heart disease in South Asian immigrants. Jounral of Transcultural Nursing, 19(2), 292-299.

Morrison, L., Guruge, S., \& Snarr, K. A. (1999). Sri Lankan Tamil immigrants in Toronto: Gender, marriage patterns, and sexuality. In G.A. Kelson \& D. L. DeLaet (Eds.), Gender and immigration. (pp. 144-162). London, UK: Macmillan Press Ltd.

Moser, D. K. (2007). The rest of life: Impact of anxiety on cardiac patients. American Journal of Critical Care, 16(4), 361-369.

Phillion, J., He, M. F., \& Connelly, F. M. (2005). Narrative and experience in multicultural education. Thousand Oaks, CA: Sage Publications, Inc.

Plach, S. K. \& Heidrich, S.M. (2001). Women's perceptions of their social roles after surgery and coronary angioplasty. Heart \& Lung, 20(2), 117-127.

Polanyi, M. (2009). The Tacit Dimension. Chicago: The University of Chicago Press. (Original work published 1966).

Public Health Agency of Canada. (2009). Tracking heart disease and stroke in Canada: Report highlights. Retrieved from: http://www.phac-aspc.gc.ca/publicat/2009/cvd-avc/reportrapporteng.php

Rajadurai, J., Lopez, E. A., Rahajoe, A. U., Goh, P. P., Uboldejpracharak, Y., \& Zambahari, R. (2012). Women's cardiovascular health: Perspectives from South-East Asia. Nature Reviews Cardiology, 9, 464-477 (August).

Schwind, J. K. (2014). Narrative Reflective Process: Giving voice to experience of illness. In C. McLean (Ed.), Creative arts in humane medicine. (pp. 125-140). Edmonton, AL: Brush Education Inc.

Schwind, J. K. (2008). Accessing humanness: From experience to research, from classroom to 
praxis. In J. K. Schwind \& G. M. Lindsay (Eds.), From experience to relationships:

Reconstructing ourselves in education and healthcare. (pp. 77-94). Charlotte, NC:

Information Age Publishing Inc.

Schwind, J. K. (2004). When nurse-teachers become ill: A narrative inquiry into the personal

illness experience of three nurse-teachers. Unpublished doctoral dissertation,

OISE/University of Toronto, ON, Canada.

Schwind, J. K. (2003). Reflective process in the study of illness stories as experienced

by three nurse-teachers. Reflective Practice, 4(1), 19-32.

Schwind, J. K., Santa Mina, E., Metersky, K., \& Patterson, E. (2015). Using the Narrative

Reflective Process to explore how students learn about caring in their nursing program:

An arts-informed Narrative Inquiry. Reflective Practice,

doi: $10.1080 / 14623943.2015 .1052385$

Schwind, J.K., Lindsay, G., Coffey, S., Morrison, D. \& Mildon, B. (2014). Opening the blackbox

of person-centred care: An arts-informed narrative inquiry into mental health

education and practice. Nurse Education Today, Special Issue NET 2013, 34(8), 1167-

1171. doi: $10.1016 / j . n e d t .2014 .04 .010$

Schwind, J., Zanchetta, M., Aksenchuk, K., \& Gorospe, F. (2013) Nursing students' international placement experience: An Arts-Informed Narrative Inquiry. Reflective Practice, 14(6), p.

705-716. doi:10.1080/14623943.2013.810619

Schwind, J. K., Cameron, D., Franks, J., Graham, C., \& Robinson, T. (2012). Engaging in narrative reflective process to fine tune Self-as-Instrument of Care. Reflective Practice, 13(2), 223-235. DOI: 10.1080/14623943.2011.626030. 1-13, iFirst Artcle.

Todero, C. M., La Framboise, L. M., Zimmerman, L. M. (2002). Symptom status and quality-oflife 
outcomes of home-based disease management program for heart failure patients.

Outcomes management, 6(4), 161-168.

Wang, W., Thompson, D. R., Chair, S. Y., \& Twinn, S. F. (2007). Chinese couples' experience during convalescence from a first heart attack: a focus group study. Journal of Advance Nursing, 61(3), 307-315.

Watkins, L., Hall, C., \& Kring, D. (2012). Hospital to home: A transition program for frail older adults. Professional Case Management, 17(3), 117-125.

Whitsitt, D. R. (2012). Coping strategies and adaptation to coronary artery bypass surgery as experienced by three couples. Heart \& Lung, 41, 350-359.

Winawer, S. J. (1998). Healing lessons. Boston: Little Brown.

Wong, F. K., Chow, S., Chung, L., Chang, K., Chan, T., Lee, W. M., \& Lee, R., (2008). Can home visits help reduce hospital readmission? Randomized control trial. Journal of Advanced Nursing, 62(5), 585-595.

Wong, F. K., Ho, M. H., Yeung, S. Y., Tam, S. K., \& Chow, S. K. (2011). Effects of a healthsocial partnership transitional program on hospital readmission: A randomized controlled trail. Social Science \& Medicine, 73(1), 960-969.

Yu, D. S., Lee, D. T., Kwong, A. N., Thompson, D. R., \& Woo, J. (2007). Living with chronic heart failure: A review of qualitative studies of older people. Journal of Advanced Nursing, 61(5), 474-483.

Zeilani, R., \& Seymour, J. E. (2012). Muslim women's narratives about bodily change and care during critical illness: A qualitative study. Journal of Nursing Scholarship, 44(1), 99-107.

Fig. 1 Marinder: Flower represents her life before illness - bright, fragrant, beautiful; dry leaf 
represents her life since illness - crumpling, fragile, alone.

Fig. 2 Karima and her illness: “I can't walk [...] my heart is damaged [...] feels crippled [...] alone. My illness is killing me."

Fig. 3 Saraja since her illness: "Sitting alone on a chair reading my Bible, thinking what to do. Children sometime come." 